Institute of $\mathbf{F}_{\text {ood and }} \mathbf{A}_{\text {gricultural }} \mathbf{S}_{\text {ciences }}$

\title{
Primer on Chemical Vegetation Management in Florida Pine Plantations ${ }^{1}$
}

Anna Osiecka, Jarek Nowak, and Alan Long ${ }^{2}$

The use of weed-control chemicals for vegetation management in forestry has increased dramatically during the last 25 years. When properly employed, herbicides can be a cost-effective tool increasing forest productivity without negatively impacting site quality. They are widely used in pine plantation management for timber and pine straw production in Florida and throughout the southeastern United States. When managing pine plantations for pine straw production, chemical weed control is practically a necessity. In Florida, this relatively new, but very profitable, commodity generates as much in annual revenue ( $\$ 80$ million) as sales of pulpwood size timber (Hodges et al., 2005). Herbicides are also used in managing forests for non-commodity objectives, such as wildlife habitat, biodiversity, recreation, or aesthetics. Native ecosystem restoration often involves herbicide use. Herbicides play an important role in controlling non-native, invasive plant species, such as cogongrass, Japanese climbing fern, kudzu, melaleuca, and many others. In pine plantation management, herbicides are most often used for the following silvicultural operations:
- site preparation before tree planting

- herbaceous weed control for plantation establishment after tree planting

- release of established pine trees from competing woody vegetation later in the rotation

Two major concerns about the environmental effects of herbicide use in forest management are: whether or not they pose a long-term health risk to the public and how they affect biodiversity. Advances in research have produced new chemical compounds, application methods and equipment, all of which make herbicide applications more effective and safer for the environment. It should be noted that forestry herbicides are applied infrequently (usually no more than three times over a 20-30 year rotation) and at low rates. Extensive research has demonstrated that they are generally characterized by low animal toxicity, low mobility, and short persistence in the environment. However, to ensure their safe use, silvicultural herbicides have to be applied in a responsible and lawful manner. This publication

1. This document is Circular 1477, one of a series of the School of Forest Resources and Conservation, Florida Cooperative Extension Service, Institute of Food and Agricultural Sciences, University of Florida. First Published: May 2005. Please visit the EDIS Web site at http://edis.ifas.ufl.edu.

2. Anna Osiecka, biological scientist, North Florida Research and Education Center - Quincy; Jarek Nowak, assistant professor, extension specialist, forestry, North Florida Research and Education Center - Quincy; and Alan Long, associate professor, School of Forest Resources and Conservation, Cooperative Extension Service, Institute of Food and Agricultural Sciences, University of Florida, Gainesville, 32611.

The use of trade names in this publication is solely for the purpose of providing specific information. UF/IFAS does not guarantee or warranty the products named, and references to them in this publication do not signify our approval to the exclusion of other suitable products. 
discusses factors that need to be considered to develop effective and safe herbicide prescriptions for pine plantation management. It also reviews some basic herbicide concepts and terminology important to understanding chemical vegetation management in pine plantations. Familiarity with this terminology is essential to understanding herbicide labels, which are legally binding documents for the herbicide use. The lists of major forestry herbicide active ingredients and examples of herbicide products registered for different forestry applications in Florida can be found in EDIS publication "Herbicides Registered for Pine Management in Florida - 2005 Update" (Osiecka et al., 2005).

\section{Why use herbicides in pine plantation management?}

The principal goal of applying herbicides in pine plantations is to enhance crop tree survival and growth rates in an economically feasible way. This goal is realized by suppressing or, less frequently, eliminating competing vegetation, hence increasing water, sunlight, and nutrient availability to crop trees. Reducing competition for site resources is especially critical for young pine seedlings. Therefore, herbicide applications are usually most effective early in the rotation, before tree planting or during the first two years after planting, when seedlings are becoming established. Effective site preparation and herbaceous weed control reduce pine mortality and provide for early and long-lasting tree growth increases. Good site preparation reduces the need for herbaceous weed control. Conversely, in the absence of adequate site preparation, pine release is necessary much earlier during the rotation. Under any management scenario, mid-rotation release further enhances pine growth and accommodates operations such as fertilization and pine straw raking. Further, herbicide application for timber stand improvement before harvest may contribute to lowering costs of timber sale preparation and logging due to improved access and visibility. It also lowers the cost of reestablishing a forest stand following harvest because of reduced amounts of residual vegetation.

The most significant tree growth response to effective chemical vegetation management is diameter increase, which also increases tree volume.
Tree height growth can also be improved, although in general it is dependent on site quality. Reduced tree mortality may result in improved stand stocking and, combined with increased tree diameter, in greater basal area. Enhanced tree growth provides a solid base for increased economic returns, because of greater merchantable timber volumes, upward shifts in product classes, and shorter rotations. Additionally, chemical weed control may provide considerable ecological benefits. For example, herbicide applications can modify the structure and composition of vegetation communities to improve wildlife habitat. They also reduce risk of destructive wildfires. At the same time herbicide applications retain vegetative biomass on site and usually cause only minimal site disturbance.

With all the potential benefits of chemical weed control, decisions to use herbicides must be based on a careful consideration of several biological, technical, and economical factors and must be a part of an overall management plan for a particular tract. A land manager should first determine if chemical weed control can meet management objectives at a similar or lower cost than other control methods. The available alternatives include mechanical weed control, prescribed burning, and grazing. However, in today's pine plantation management, herbaceous weed control and release of young pines are accomplished almost exclusively with herbicides. In general, herbicide treatments provide longer-lasting weed control and better growth response of crop trees than fire or mechanical methods. Chemical weed control also tends to be less expensive and less destructive to the site than mechanical methods. Effective vegetation management often combines herbicide applications with prescribed fire.

On many sites, combining chemical vegetation management with other silvicultural practices, like fertilizing, results in maximum growth gains. Fertilizers can even be combined with herbicides in a single application, either in a mixture or as a carrier impregnated with certain soil herbicides (e.g., hexazinone, sulfometuron methyl or pendimethalin). At mid-rotation, herbicides are often applied in conjunction with fertilization and thinning. 


\section{Factors considered in developing herbicide prescriptions for pine plantations}

Herbicide prescription is a complex process that involves matching a suitable herbicide treatment with a specific silvicultural operation objective and an overall management objective. One should attempt to select the treatment which can be expected to provide the maximum weed control with minimum environmental hazard at the lowest cost. It is not always possible or even necessary to choose a single "best" treatment. However, the herbicide treatment must be effective, economically feasible, legal, and not detrimental to the crop trees, environment or humans. Therefore, in designing a herbicide treatment, the forest manager has to carefully evaluate the intended silvicultural operation, crop trees, weeds, soil and site conditions, environmental and personal safety, as well as herbicide characteristics. The prescription must include the herbicide(s), application method, application rate(s), and timing.

Besides site specific variables, consideration should be given to physiographic sub-region. General topography, prevalent vegetation, and soils may render some treatments more applicable than others. For example, herbicide treatments in Florida flatwoods will often be different than on sandhill sites.

\section{Silvicultural Operation}

When selecting a herbicide for site preparation, primary concerns are good vegetation control and residual soil activity rather than plant selectivity. Application timing and/or planting dates must be adjusted according to the waiting periods recommended by the label before planting crop trees. On the other hand, if the objective is herbaceous weed control or pine release, special care has to be taken to prevent damage to the crop trees already present on the site. Therefore one has to consider first of all herbicide selectivity, and choose an appropriate application method, rate, and timing.

Many forestry herbicides can be used for different silvicultural operations, while others are labeled for a specific application. For example, Arsenal ${ }^{\circledR}$ AC (imazapyr) is labeled for site preparation, herbaceous weed control, conifer release and individual stem treatments. On the other hand, OneStep ${ }^{\circledR}$ (glyphosate with imazapyr) is only labeled for site preparation. Most triclopyr formulations are labeled for individual stem treatments, site preparation and directed spray for conifer release, but not for herbaceous weed control.

Sometimes more than one operational objective can be accomplished by one herbicide treatment. Combining site preparation with the first year herbaceous weed control is highly cost-effective. For example, inclusion of sulfometuron in fall site preparation may provide good residual herbaceous weed control early in the following growing season. Conifer release late in the rotation may result not only in timber stand improvement before harvest but also contribute to harvest efficiencies and to subsequent site preparation.

\section{Crop Trees}

A herbicide can only be used for those crop species which have been specified on the label for a particular silvicultural operation. Label violation may result in crop tree damage as well as litigation. Of the three most commonly cultivated pine species in Florida, generally loblolly pine is the most tolerant to forestry herbicides, whereas longleaf pine is the least tolerant. There are fewer herbicide treatments that can be safely applied in longleaf or slash pine than in loblolly pine plantations. For example, metsulfuron methyl or atrazine should not be used for longleaf pine at any rate. Some herbicides, such as imazapyr, should be applied at lower rates for slash and longleaf pine, to prevent terminal dieback and inhibition of height growth.

The degree of crop tree sensitivity to many herbicide products depends on tree age and growth phase. In general, the youngest pines are the most sensitive. Therefore, sensitivity of crop tree species is especially critical in designing herbaceous weed control treatments because herbicides are applied over-the-top or in the vicinity of young pine seedlings. For example, an effective imazapyr/sulfometuron methyl tank mix is not recommended for herbaceous weed control in 
longleaf or slash pine. Imazapyr has to be used at very low rates during the first two growing seasons after planting longleaf pine seedlings. Glyphosate can only be applied to pines which have been established for more than one year and are not actively growing (prior to initial bud swelling in the spring or after formation of final resting buds in the fall). In general, pine sensitivity to herbicides increases during periods of intensive growth. Slash pine is particularly sensitive to herbicide applications during and immediately following growth flushes. For example, newly elongated shoots may die back as a result of imazapyr application. Physiological condition and vigor of crop trees also affect their herbicide tolerance. Trees under stress caused by drought, prolonged flooding, disease, insect infestation, animal damage, etc. are more likely to sustain herbicide damage.

\section{Weeds}

For the purpose of this publication the word "weed" is defined as any undesirable plant. It is critical to identify and quantify dominant weed species on the site before prescribing a herbicide treatment. The urgency of controlling a particular species does not only depend on its density on the site but also on its size, growth habit, vigor, potential for re-growth and spreading, allelopathy (toxicity to other plants), or being a known alternative host of an important disease. For example, even a very small amount of cogongrass justifies prescribing herbicide treatment in an attempt to eradicate it from the site before it spreads more widely. When assessing the vegetation complex on the site it is necessary to inspect the surrounding area for weeds which may invade the site in the future. It is also useful to know the land use history. Weed seeds and even vegetative parts may survive in the soil for a very long time and become a problem on the site once conditions for their growth are suitable.

Prioritizing weed species for herbicide control and designing effective herbicide treatments require familiarity with weed taxonomy, growth cycles, and reproduction methods. Taxonomically, most weeds important in forestry are vascular plants. Within this group a few are ferns (e.g., Japanese climbing fern), some are gymnosperms (represented by conifers), but the majority are angiosperms (flowering plants). The angiosperms are divided into two classes: monocots (including grasses, sedges, rushes, palms, and yuccas) and dicots (broadleaf plants). Several herbicides control both broadleaf weeds and grasses. Some are effective only against broadleaves (e.g., triclopyr, 2,4-D, clopyralid, dicamba, fluroxypyr), or grasses (e.g., fluazifop-P-butyl, clethodim, sethoxydim). Most products are less effective against conifers than against angiosperms. If residual pines have to be controlled during site preparation, the best choice in Florida is applying glyphosate.

Based on the length of their life cycle, weeds can be classified as annual, biennial, or perennial. There are numerous species of annual and perennial broadleaf weeds, grasses, and sedges. Relatively few weed species are biennial. The life cycle of annual weeds may begin at different seasons of the year. Summer annuals germinate from seed in the spring and mature before winter of the same year. Winter annuals germinate in the fall and complete their life cycle by summer of the following year. Biennial weeds germinate in the fall and develop roots and a cluster of leaves during the first year after germination. During the second year, they develop flowers, produce seed, and die. Perennial weeds live for more than two years. Most survive winter in a dormant stage. In a subtropical climate, such as in south Florida, some perennials become dormant during summer. Herbaceous perennials usually lose their above-ground stems and foliage during the winter and regenerate from underground roots and/or stems in the spring. Woody perennials retain their woody stems throughout the winter and either lose foliage (deciduous) or preserve it (evergreen). Most perennial weeds, especially herbaceous, reproduce by vegetative organs such as bulbs, stolons, rhizomes, tubers, or roots. Many also spread by seed, either in addition to vegetative propagation or as a main reproduction method. Most trees and shrubs spread mainly by seed. Because of their great persistence and reproductive potential, perennial weeds are the most difficult to control. Some herbicides (e.g., atrazine, paraquat, simazine, and pendimethalin) are only capable of controlling annual weeds. In an established plantation, perennials, especially shrubs and hardwood trees, are usually the most prevalent weeds. At the time of site preparation before tree 
planting and during the first years of plantation establishment, composition of weed community to a large degree depends on the previous land use.

Besides systematic classification, herbicide recommendations often refer to additional weed categories. "Brush" is a term for unwanted woody growth that includes shrubs and small trees. "Vines" are very vigorous plants with climbing or creeping stems. "Brambles" include several species in the genus Rubus (blackberries and raspberries), usually characterized by thorny or bristly stems. Sometimes wild rose (Rosa spp.) is placed in the same category. "Forbs" is a term often used for herbaceous broadleaf plants.

Different ways of grouping weeds in herbicide label recommendations may create some confusion. On most labels woody plants are listed separately. In some cases vines and brambles are considered a special category (e.g., on Arsenal@ AC label), because of a particular difficulty in controlling them. On some labels, there is only a distinction between herbaceous and woody plants (e.g., Velpar® L). In other cases, the distinction is also made between grasses and broadleaf species or between annual and perennial weeds.

Besides recommendations referring to entire groups of weeds, herbicide labels usually also provide detailed lists of weed species controlled by a given herbicide. In such listings, weed susceptibility to the labeled product is often rated from "highly susceptible" to "resistant". Most weeds fall between these two extreme categories, but it may be hard to accurately specify intermediate degrees of weed control by a given product.

In addition to weed species, the degree of control depends on weed density, size and maturity, as well as herbicide application rate. Hard-to-control species or dense, larger, or more mature weeds require higher recommended herbicide application rates to obtain the same degree of control compared with more susceptible species, or sparse, smaller, less mature plants. It is difficult to pinpoint the amount of weed control necessary to produce the desired silvicultural results. As a general rule, 50-70\% control of major weed species on a site is considered satisfactory in many situations. The acceptable level of weed control varies greatly and depends, among other factors, on the operational objective, weed species, and density. Whereas $50 \%$ control of high density undesirable woody vegetation may be acceptable for a pine release treatment, minimums of $70 \%$ weed control may be required to prepare a site for tree planting and $95 \%$ may be necessary for invasive exotic species.

Very often application of herbicide mixtures is necessary to obtain a desired degree of weed control. This is especially true where diverse vegetation is present on a site. Although any combination of herbicides can be legally mixed if each is labeled for the intended application and the mix is not prohibited by any of the labels, it is important to select compatible products and mix them properly. Labels provide recommendations on acceptable herbicide combinations and instructions for mixing. Improper herbicide mixing may result in phase separation or even herbicide deactivation (e.g., when mixing glyphosate and triclopyr). On the other hand, certain herbicides may be more effective when applied together. For example, there is a documented synergism between fluroxypyr and triclopyr resulting in improved control of key woody species. When mixing herbicides, one has to use the most restrictive limitations from labels of all mixed products.

\section{Soil Conditions}

The efficacy and safety of soil-active herbicides strongly depend on the soil texture, organic matter content, $\mathrm{pH}$, soil drainage properties, and presence or absence of hardpan. Fine-textured soils (clays) and organic soils have higher adsorptive capacity than coarse-textured (sandy), mineral soils. Therefore, soils with high clay and/or organic matter content have a higher tendency to bind herbicides, making them less available for uptake by plant roots. As a result, higher herbicide rates may be necessary to obtain a satisfactory degree of weed control on these soils. On the other hand, on sandy soils, lower herbicide rates should be applied to avoid damage to crop trees and/or herbicide leaching to groundwater. Most soil-active herbicide labels provide rate recommendations for various soil types. While designing a herbicide treatment, it is necessary to determine the soil type the treatment is intended for, and follow rate specifications accordingly. Sites with 
variable soil types present a unique challenge for adjusting the herbicide rates.

Soil $\mathrm{pH}$ is another soil characteristic that affects activity and mobility of some herbicides. For example, sulfometuron methyl activity significantly increases at higher $\mathrm{pH}$. Therefore, it should be applied at lower recommended rates on soils with $\mathrm{pH}$ between 6.2 and 6.5 and should be avoided if soil $\mathrm{pH}$ exceeds 6.5. Presence of a soil hardpan, especially a shallow one, may also restrict the use of soil-active herbicides for pine release. It increases the danger of pine mortality, since pine roots tend to spread out at the level of the hardpan, where the herbicide may concentrate.

\section{Environmental and Personal Safety}

When prescribing a herbicide treatment, one has to seriously consider all potential effects with regard to the target site, and also the adjacent sites, especially such sensitive areas as croplands, grazing lands, wetlands, water sources and inhabited or public areas. Herbicide movement from the application site to any of the sensitive areas constitutes a label violation and can result in litigation. Such movement can occur through drift of fine spray particles during application, movement of volatilized herbicide during or after application, movement in surface water, leaching to the groundwater or movement with soil. These risks can be minimized by selecting herbicides with appropriate active ingredients and formulations, choosing appropriate application methods and timing, and using the lowest effective application rates, particularly while operating in close proximity to sensitive areas.

Applying liquid herbicides, especially from the air, may result in unintentional herbicide drift. The interaction of many equipment- and weather-related factors determines the potential for spray drift. Drift potential increases as wind speeds increase, especially under gusty conditions. The best drift management strategy is to apply the largest droplet size that provides sufficient coverage and weed control. Application of agriculturally registered drift control agents or high viscosity invert emulsions may be helpful too. Additional precautions (e.g., maintaining continuous smoke column to detect air movement or temperature inversions) may be advisable when applying highly phytotoxic herbicides (e.g., triclopyr). Under adverse conditions, it may be necessary to restrict aerial application to the interior of the tract and treat the buffer around it from the ground. In high risk areas aerial applications should be avoided completely.

The danger of herbicide volatilization increases with increasing air temperatures during and immediately following application. Of the common forestry herbicides, only triclopyr and 2,4-D can pose significant volatilization risk. In general, ester formulations are more volatile than amines.

Preventing surface water and groundwater contamination is particularly important. More than $90 \%$ of Florida's population depends on groundwater for potable uses. Much of Florida's forestland encompasses aquatic areas or is in groundwater recharge areas. The potential for a herbicide to negatively impact quality of surface water (through runoff) or groundwater (through leaching) depends on a combination of soil and herbicide properties, along with weather conditions and management practices. In this regard, important soil properties include: hydraulic permeability, organic matter content, and slope. Leaching is more likely to occur in flat areas of permeable sandy soils, whereas runoff may be expected on slopes of fine-textured, less permeable soils. The two herbicide properties that most affect its potential to contaminate surface water or groundwater are solubility and persistence.

If applied directly to soil, more of a herbicide may be prone to leaching and runoff as compared with foliar applications. Sensitive crops can be severely injured when soil treated with certain soil herbicides is washed onto land where these crops are grown, or when treated soil is blown or moved there. Crops can also be injured by irrigation with the water from a lake or a pond contaminated with certain herbicides.

Most silvicultural herbicides are for terrestrial uses and should not be applied directly to water or to areas where surface water is present. A few exceptions of forestry herbicides labeled for aquatic areas include: Accord ${ }^{\circledR}$ Concentrate, Glypro ${ }^{\mathrm{TM}}$, Rodeo ${ }^{\circledR}$, and Habitat ${ }^{\circledR}$. The aquatic toxicity is 
determined by an active ingredient and a formulation. Some ester formulations (e.g., Garlon 4) are much more toxic to aquatic organisms than the amine formulations (e.g., Garlon 3A). Surfactant may also increase herbicides toxicity to aquatic organisms. For example, glyphosate formulations with surfactants (e.g., Glypro ${ }^{\mathrm{TM}}$ Plus or Accord ${ }^{\circledR} \mathrm{SP}$ ) are more toxic to aquatic organisms than the formulations containing no surfactants (e.g., Glypro ${ }^{\mathrm{TM}}$ or Accord ${ }^{\circledR}$ Concentrate).

Herbicide applications affect wildlife habitat to various degrees, depending on their selectivity and application rate and method. These indirect effects on wildlife are temporary even in cases where most target vegetation has been eliminated through broadcast application of a broad spectrum herbicide at the highest labeled rates. In the areas where enhancement of wildlife habitat is a management objective, herbicide applications can be manipulated to promote plant species suitable for wildlife food and cover. Direct impact of forestry herbicides on wildlife is usually minimal, due to their generally low toxicity to mammals and birds, relatively low application rates, and relatively short persistence in the environment.

Because of generally low toxicity to humans, forestry herbicides, when used in accordance with their labels, present very little danger to persons applying them. With regard to acute oral toxicity, all forestry herbicides (with the exception of paraquat and marginally 2,4-D formulations) are either Category IV or Category III pesticides. Despite low oral toxicity, the signal word "Danger" appears on labels of several herbicides (e.g., containing hexazinone) because of the potential for causing eye damage. The reported $\mathrm{LD}_{50}$ values refer to undiluted herbicides. Toxicity decreases when herbicides are mixed with a carrier. It should be noted that many everyday use products are more toxic than forestry herbicides. For example, pure caffeines oral $\mathrm{LD}_{50}$ of $200 \mathrm{mg} / \mathrm{kg}$ makes it a Category II substance.

Herbicide labels provide directions for use, user safety recommendations, and first aid procedures. They also list Personal Protective Equipment (PPE) for applicators and other handlers. Material Safety Data Sheets (MSDSs) contain additional information on personal and environmental safety. A herbicide which may pose a risk to human health or the environment, even when applied in accordance with the label, is classified as Restricted Use Pesticide (RUP). The statement "Restricted Use Pesticide" prominently appears at the very top of the herbicide label front panel. The use of RUPs is limited to certified applicators, specially trained in handling and applying pesticides, or persons under their direct supervision. The only RUPs, relatively rarely used in forest management, are formulations of atrazine (due to ground and surface water concerns) and paraquat (due to acute toxicity).

\section{Herbicide Characteristics}

Knowledge of chemical and physical properties of herbicides and their effects on biological systems enables the selection of appropriate products, application methods, rates, and timing to ensure effective weed control achieved in a safe manner. When designing herbicide treatments one has to consider several important herbicide characteristics including selectivity, activity, mobility in soil, volatility, persistence in the environment, and toxicity. These characteristics are determined not only by the active ingredient(s) but also by the formulations in which the active ingredients are 'packaged'.

Active ingredients (a.i.) have the greatest influence on the properties and behavior of the herbicide, since they are the chemical substances designed to negatively impact the undesirable vegetation. Active ingredients for several liquid forestry herbicides are available in amine and/or ester forms:

- Esters are oil soluble and can penetrate plant tissues (especially woody tissue) more readily than amines. Hence, esters may be a formulation of choice on sites where weeds with waxy leaves prevail or for bark applications.

- Amines are water soluble and are therefore more easily transported within plants than esters. They typically require a surfactant to facilitate penetration through waxy or thick plant surfaces. In general, amines are less volatile than esters and thus are preferable in the vicinity of sensitive sites. 
Formulations are the commercial preparations of herbicides. They may contain one or more active ingredients, adjuvants, and inert ingredients. Since most of the active ingredients of forestry herbicides are no longer protected by patents, chemical companies have been developing new herbicide formulations, often including proprietary surfactants and/or other adjuvants. These new formulations are usually more effective, easier to use and/or more environmentally friendly than the older ones. Water dispersible granules (also called extruded pellets) are an example of a relatively new solid formulation providing superior suspension within the water carrier. Because of the multitude of existing herbicide formulations, one has to make sure that the selected formulation is appropriate for the desired application. The important determining factors include application method, target weed species, crop tree species, and environmental considerations. Knowing the formulation helps the applicator to properly dispense herbicide(s) in an appropriate carrier, add appropriate adjuvants, if needed, and adjust the application method accordingly. Forestry herbicides are manufactured as liquid or solid formulations.

- Liquid formulations may be used undiluted or may be mixed with water or oil carriers to prepare a spray solution or emulsion. In a solution a herbicide is dissolved in a carrier and will not separate over time. In an emulsion, the herbicide is suspended as minute globules in a carrier and the two phases will separate over time. Emulsifying agents are used to prevent the separation during mixing and application. The two most common liquid formulations for forestry herbicides are

- Water-soluble liquids which are mixed in water to form a spray solution;

- Emulsifiable concentrates which contain a petroleum solvent for the active ingredient and can be mixed either in water (emulsion) or oil (true solution).

- Solid formulations may be applied as solutions, suspensions, or solids.
- Soluble powders form a homogenous solution in water.

- Water-dispersible granules (dry flowables) typically disperse (but do not dissolve) in water, and generally require agitation to prevent precipitation in the spray tank.

- Wettable powders are suspended in water through constant agitation and applied as a spray.

- Granules and pellets consist of active ingredient(s) absorbed onto coarse particles of an inert ingredient, such as clay. When applied to the soil they slowly dissolve, gradually releasing active ingredient(s).

Adjuvants are chemicals included in a commercial formulation or added to a tank mix immediately preceding an application to enhance mixing, application, or herbicide efficacy. Many herbicide formulations contain surfactants, buffers, and other adjuvants. Adding an adjuvant at the time of application enables an applicator to customize a formulation to be most effective in a particular situation. Adjuvants improve herbicide efficacy or optimize applications by increasing spray deposition, reducing bounce and run-off, minimizing evaporation, resisting wash-off, enhancing absorption, reducing drift, marking treated areas, minimizing foaming, or mitigating herbicide incompatibility. Adjuvants include surfactants, deposition aids, extenders, activators, buffers and acidifiers, drift control agents, spray colorants, anti-foaming agents, and compatibility agents. Before adding adjuvant(s) to a herbicide it is necessary to refer to the labels of all products to ensure their compatibility. While adjuvants may improve herbicide performance, they may also affect crop species tolerance. Some surfactants increase herbicide absorption by pines, thus decreasing selectivity. For example, longleaf pine seedlings may be damaged if sprayed over-the-top with a solution containing certain surfactants.

Surfactants (Surface-active agents) are materials that modify the properties of a liquid medium at a surface or interface. It is a general term 
for a group of adjuvants including spreaders, stickers, emulsifying agents, and crop oil concentrates. Often the term surfactant is used in reference to spreaders (wetting agents), which are added to spray mixtures to decrease the surface tension, causing a larger portion of each spray droplet to come into contact with the surface of the target vegetation. Reducing surface tension results in enhanced wetting and penetration by a herbicide. Ionic spreaders mixed with water physically separate into negative and positive ions, which may react unfavorably with ionic herbicides. Nonionic spreaders do not separate into ions when mixed with water and therefore are not likely to react with herbicides. Since most herbicides are ionic, it is safer to use nonionic surfactants in most cases.

Selectivity refers to the herbicide capability to affect different classes of plants in a different manner due to physiological and/or morphological differences between them. Ideally, differences between crop plants and weed species are exploited. Selective herbicides target a particular class of plants, for example broadleaf (e.g., fluroxypyr) or grasses (e.g., fluazifop-P-butyl). Non-selective herbicides (like glyphosate) negatively affect plants by working on metabolic processes common to most plant groups and thus should not be used over-the-top of crop trees, especially during periods of active growth. It is particularly important to use selective herbicides, that do not affect pines, during herbaceous weed control. Selectivity may also be achieved by manipulating application method, rate, and/or timing. For example, one can control undesirable trees by directly spraying their base or foliage with a non-selective herbicide without damaging crop trees. Also, some herbicides at lower rates may selectively control unwanted vegetation without affecting the pines. Non-selective herbicides can often be safely applied over-the-top of crop trees during their dormancy.

Activity refers to the way a herbicide enters treated plants:

- Foliar-active herbicides are usually absorbed by foliage and typically require adequate leaf surface area in order to be effective. Some of them can also be applied to stems and absorbed through bark or epidermal tissues. Many foliar-active herbicides can be injected directly into tree stems, or applied to wounds, which expose cambium and vascular tissues. These methods include treating surfaces of cut tree stumps. Foliar herbicides exhibit post-emergence weed control.

- Soil-active herbicides are taken up from the soil by the roots together with the water and are transported in the xylem to the upper parts of the plant. They generally require adequate soil moisture for activation. For annual and herbaceous perennial plants, these are usually most effective when applied pre- or early post-emergence, but soil active herbicides (such as hexazinone and imazapyr) are also important for control of perennial species (including woody plants) during the growing season.

Some products exhibit only foliar activity (e.g., 2,4-D, glyphosate, fluazifop-P-butyl and fosamine). There are no exclusively soil-active herbicides. Atrazine is soil-active with limited foliar activity. Some other herbicides can be characterized as mostly soil-active with some foliar activity (e.g., hexazinone and sulfometuron methyl). A few herbicides are almost equally active in the soil and as foliar sprays (e.g., imazapyr and metsulfuron methyl).

Mobility in soil, associated with water solubility, indicates a chemical's potential for off-site movement through leaching and runoff. Solubility is inversely related to soil sorption, which can be quantified by several indices including:

- $\mathbf{K}_{\mathbf{d}}$ (Soil sorption coefficient) defined as the ratio of sorbed pesticide to dissolved pesticide at equilibrium in water/soil slurry;

- $\mathbf{K}_{\mathbf{O C}}$ (Soil organic carbon sorption coefficient) calculated as $\mathrm{K}_{\mathrm{d}}$ divided by the weight fraction of organic carbon present in the soil.

Pesticides with small $\mathrm{K}_{\mathrm{OC}}$ values are more likely to be leached compared with those with large $\mathrm{K}_{\mathrm{OC}}$ values. However, $\mathrm{K}_{\mathrm{OC}}$ values should be used with caution, since they may be significantly affected by soil properties and environmental factors.

Volatility refers to a chemical's tendency to go into a gaseous phase during or after application and is 
primarily determined by its molecular weight. High volatility may result in herbicide movement off-site with negative impacts on nearby sensitive crops.

Persistence defines the "lasting-power" of a chemical and is measured in half-life. Half-life $\left(\mathbf{T}_{\mathbf{1 / 2}}\right)$ can be defined as the expected time after application during which half of the applied chemical would be deactivated. The half-life values for herbicide active ingredients are derived from field and laboratory experiments. These values give only a rough estimate of the persistence of a herbicide in the environment, since an actual half-life of a particular product also depends on a formulation and can vary significantly depending on soil characteristics, weather (especially temperature and soil moisture), and vegetation at the site. Nonetheless, average half-life values, based on herbicide deactivation in surface soils, provide some means of comparing the relative persistence of herbicides. The $\mathrm{T}_{1 / 2}$ values in subsoils and ground water are usually much larger and often not available.

Toxicity refers to a chemicals potential to cause injury, illness, or other undesirable effects in mammals, birds, fish, honey bees or other organisms. The two most frequently used toxicity measures are median lethal dose $\left(\mathrm{LD}_{50}\right)$ and median lethal concentration $\left(\mathrm{LC}_{50}\right)$.

- $\mathbf{L D}_{\mathbf{5 0}}$ is the dose (quantity) of a chemical that kills $50 \%$ of a population of test animals through oral or dermal exposure and is expressed in milligrams of the chemical per kilogram of the test animal body weight.

- $\mathbf{L C}_{\mathbf{5 0}}$ is the chemical's concentration in the air (inhalation toxicity), in the water (aquatic toxicity), or continual exposure in the diet that kills $50 \%$ of a population of test animals and is expressed in milligrams of the chemical per liter of air, water or food (parts per million).

The detailed herbicide toxicological characteristics (including ecotoxicology) are included in Material Safety Data Sheets (MSDSs) and in Pesticide Information Profiles (PIPs) in EXTOXNET. Based on toxicity studies, an appropriate Signal Word and "Hazards to Humans and Domestic Animals", "Personal Protective Equipment" and "First Aid" statements appear at the beginning of a herbicide label. The technical literature most often compares herbicides with regard to mammalian oral toxicity categories according to following classification:

\begin{tabular}{|cll|}
\hline \hline Category & $\begin{array}{l}\text { Signal } \\
\text { Word }\end{array}$ & $\begin{array}{l}\text { Oral LD } \\
\text { (mg/kg) }\end{array}$ \\
\cline { 2 - 3 } I & Danger & up to 50 \\
II & Warning & $>50-500$ \\
III & Caution & $>500-5000$ \\
IV & Caution & $>5000$ \\
\hline \hline
\end{tabular}

\section{Application Method}

For a herbicide to be effective and safe it must be applied by an appropriate method. The economic feasibility of the herbicide treatment also depends on the availability of a suitable application method.

There are three general types of application techniques that can be used for both foliar-active and soil-active herbicides: broadcast, banding, and spot treatments.

- Broadcast treatments are applied to an entire area either from the air (with helicopter and less frequently fixed wing aircraft) or from the ground (with machine-mounted or hand-held equipment). Broadcasting is the method of choice for site preparation, but can also be used for conifer release and herbaceous weed control.

- Band treatments are applied in strips on or along rows of crop trees from the ground with machine-mounted or hand-held equipment. Band application is often as effective as broadcast treatment for herbaceous weed control in young plantations and may result in significant cost reduction. Banding is usually more effective in controlling annual than perennial weeds.

- Spot treatments are applied to individual stems or small areas, usually with back-pack sprayers or other hand-held devices. They can be as effective as broadcast, yet use much less herbicide and thus can offer substantial savings in herbicide costs and have less impact on the environment. Spot treatments are very labor intensive, however, and usually can only be justified for small tracts or when a small number of problem spots are to be treated. 
Foliar-active herbicides can be spot-applied as directed sprays or by various individual stem methods:

- Directed spray is a spot treatment used mostly for conifer release and sometimes for herbaceous weed control. Spray is directed from back-pack sprayers to the foliage or stems of the target plants without contacting crop trees. Instead of spraying, the herbicide can be wiped onto the weeds with a wick applicator reducing the potential for drift or spraying non-target plants.

- Individual stem treatments encompass various methods of applying herbicides directly to target plant stems.

- Basal bark sprays involve spraying intact bark with a herbicide. Ester formulations dispersed in an oil carrier are most effective for this method.

- Thinline (or streamline basal) spray involves applying a herbicide in a narrow band, 6-24" above the stem base and is used for small-diameter stems.

- Spray-to-wet (or full basal) spray involves spraying the lower 12-20" of the plant to the point of runoff and can be effective for slightly larger-diameter stems.

\section{- Frill girdle (or hack \& squirt)} involves cutting or drilling through the tree bark into the sapwood and immediately applying a herbicide to the cut. This application is effective for larger-diameter trees and does not require an ester formulation.

- Injection consists of injecting a herbicide through the bark into the vascular system of target trees using specialized injection devices.

- Cut stump method consists of applying a herbicide to the entire cambium and inner bark of a stump, immediately after cutting off the stem.
It is often used for woody species which have a tendency to re-sprout after being cut. It is usually more efficient to prevent sprouting than to control it later.

Soil-active herbicides (liquids and solids) can be spot-applied in a grid pattern, around individual crop trees, or at the base of individual stems of competing vegetation:

- Grid application involves applying soil-active herbicide to an entire area using a grid pattern. Selection of a grid pattern and herbicide rate depends on soil texture and woody plant composition. It can be used for site preparation and conifer release, especially on sites with large numbers of stems per acre.

- Spot-around and Tree-centered spots involve applying soil-active herbicides around the crop trees, in small spots or to a small area around a tree, respectively, to control woody and herbaceous vegetation, respectively.

\section{- Individual stem treatment (basal soil)} involves applying herbicides to the soil in a close proximity to the stem of target woody plants.

Herbicide labels specify application methods registered for each herbicide. Other methods may also be legal, unless the label specifically prohibits their use. It is advisable to consult with a product manufacturer, distributor, or extension agent before using an application method not listed on the product label. Besides legal ramifications, several other factors affect the choice of application method. Safety considerations in regard to application method have been previously discussed in some detail.

Tract size is a decisive factor not only in selecting an application method but also in the possibility of contracting a commercial applicator. Commercial applicators that operate specialized equipment prefer to treat large forested tracts since their cost per acre decreases with the increasing number of acres treated at one location. Large tracts 
are best suited for aerial applications or the use of heavy ground machinery. For tracts that are not easily accessible by ground, aerial applications may be the only practical means of herbicide treatment irrespective of tract size.

Stand density and structure may also dictate an application method or its modification. Applying foliar-active products from the air to a dense stand with multi-story canopies may result in inadequate coverage of the lower layers of vegetation. In such cases, it may be necessary to increase spray volume, use a soil-active granulated herbicide, or to resort to a ground application. However, mechanized ground applications require a site that is not overgrown with hardwoods. The crews and equipment must be able to move at a uniform speed through the site to be able to apply herbicides at a specific rate per unit area. If this is not possible, backpack applications could be a solution. Backpack applications can also be used for areas too small for efficient aerial or ground machine-mounted broadcasts, areas missed by other methods, for spot treatments, or to treat buffers near sensitive areas. Landowners who have the time and manpower to apply herbicides themselves may choose this method. Backpack application is very labor intensive, especially on sites with dense understory growth, which are hard to traverse. Effective backpack application is particularly difficult if the target vegetation is taller than six feet. In that case, it may be necessary to use prescribed fire or mechanical mowing to open up the stand before herbicide application. Re-sprouting shoots can easily be treated with a herbicide. One of several individual stem methods described above can be used if only a few large hardwoods have to be controlled.

\section{Application Rate}

Herbicide labels list ranges of application rates that are legal for a particular silvicultural operation, crop tree species, or soil type. Rates for most application methods are expressed in units of volume (liquid formulations) or mass (solid formulation) of a commercial product per unit area of a treated tract. However, rates may also be expressed as units of active ingredient per unit area, and applicators must be sure to recognize the differences between formulation versus a.i. rates. Most labels list broadcast application rates. For band applications, amount of herbicide applied per acre has to be reduced according to the area of treated bands. Many labels also recommend rates for treatments that are applied in a grid pattern. Rates for directed spray and individual stem treatments are usually expressed as concentration, and sometimes additionally as amount of spray solution per size unit of target vegetation (tree stem diameter or canopy width of multi-stemmed brush). Even in these cases maximum labeled rates per acre listed for crop species must not be exceeded.

In general, highest application rates are recommended for site preparation and lowest rates for herbaceous weed control. Often labeled rates are higher for loblolly pine than for slash or longleaf pines. Higher rates of soil-active herbicides are recommended for fine textured (clay) and/or organic soils than for coarse textured (sandy), mineral soils. Within recommended ranges, herbicides should be applied at higher rates for hard-to-control species, denser, larger and more mature weeds. Many labels recommend application rates that are necessary for satisfactory control of particular weed species. In every situation one should select the lowest application rate that can provide an acceptable level of weed control.

\section{Application Timing}

Although some herbicides may be used throughout the growing season, time of application is critical for effectiveness of many herbicide treatments. Since foliar products are absorbed into the plant primarily through leaf surfaces, they must be applied after weeds have fully developed foliage in the spring, but before fall leaf drop. Because some foliar herbicides are most effective when treated plants are at peak physiological activity, reduced efficacy may be expected when applied during a cold, wet spring. Foliar activity may also be reduced when target vegetation is dormant, semi-dormant, or under stress. Certain foliar products (e.g., imazapyr/glyphosate mixtures) are most effective in late summer and fall.

It is important that foliar herbicides not be applied immediately before rainfall, which may wash off the product before it has been absorbed by the 
plant. Usually ester formulations are more rain-proof than amines. Surfactant additions also improve herbicide rain resistance. Some labels recommend minimum time intervals between application and rainfall. If this interval has not been observed, a repeated application may be necessary for acceptable weed control. To reduce potential for evaporation and spray drift, one should avoid spraying herbicides at temperatures above $85^{\circ} \mathrm{F}$, under gusty or windy conditions, or during temperature inversions. Labels generally provide additional information about weather conditions for aerial applications.

Since soil-active herbicides are taken up by the root system, they are usually applied in the spring or early summer, when rainfall needed for herbicide activation is more likely to occur. They are also most effective before weed emergence or shortly thereafter, before the weeds mature. Hexazinone is an example of a herbicide most effective when applied in spring/early summer during periods of frequent rainfall and of rapid plant growth. Not enough precipitation can result in low activity of soil-active herbicides. At the same time, prolonged periods of dry weather preceding herbicide application in the spring or during the previous fall may result in drought stress conditions, hence increasing the possibility of crop tree damage during herbaceous weed control or pine release. On the other hand, too much rain can wash herbicides off-site, or move them deep into the soil profile before target species can absorb them. This may result in diminished weed control and/or cause environmental problems.

\section{Summary}

Herbicide use in pine plantation management in Florida and the southeastern U.S. has increased significantly since the 1980 s. Their use will probably continue to increase in step with more intensive management of pine plantations. To reduce potential environmental hazard, and at the same time meet management objectives, a skilled forest manager must always carefully consider the relevant factors discussed in this publication before developing a herbicide prescription most suitable for a particular situation. Equally important for effective and safe herbicide treatment is a faithful execution of the developed prescription by a skilled and conscientious applicator. The single most important rule in employing herbicides is to always read and follow the label instructions.

In Florida, specific herbicide questions can be directed to County Extension Agents. A list of Cooperative Extension County Offices of the University of Florida, Institute of Food and Agricultural Sciences (IFAS), with links to their Web pages, is available at http://extadmin.ifas.ufl.edu/Extlinks.htm.

Herbicide-related information can also be obtained from the IFAS Pesticide Information Office (PIO), accessible through http://pested.ifas.ufl.edu. Regulatory aspects of herbicide use in Florida are administered by the Florida Department of Agriculture and Consumer Services (FDACS) Division of Agricultural and Environmental

Services, which is accessible at http://www.flaes.org/.

Nationally, the Environmental Protection Agency (EPA) - Office of Pesticide Programs administers herbicide use and provides technical information accessible at http://www.epa.gov/pesticides/. Additional sources of information about a wide variety of herbicide-related subjects include the National Pesticide Information Center (http://npic.orst.edu/index.html) and EXTOXNET (The EXtension TOXicology NETwork, at http://extoxnet.orst.edu/.)

\section{References}

USDA Forest Service. 1994. Pest and Pesticide Management on Southern Forests. Management Bulletin R8-MB 60. Southern Region. Atlanta, Ga., $46 \mathrm{pp}$.

Campbell, P. and A. Long. 1998. Vegetation Management in Florida's Private Non-Industrial Forests. SS-FOR-10. Florida Cooperative Extension Service, IFAS, University of Florida, Gainesville, Fl., $11 \mathrm{pp}$.

Cantrell, R.L. 1985. A Guide to Silvicultural Herbicide Use in the Southern United States. Auburn University School of Forestry, Alabama Agricultural Experiment Station, Auburn, Al., 592 pp. 
CDMS Labels \& MSDS. 2005.

http://www.cdms.net/manuf/ (accessed March 2, 2005).

Ferrell, J.A., G.E. MacDonald, B.J. Brecke, A.C. Bennett, and J. Tredaway Duncar. 2005. Using Herbicides Safely and Herbicide Toxicity. SS-AGR-108. Florida Cooperative Extension Service, IFAS, University of Florida, Gainesville, Fl., 9 pp.

Ferrell, J.A., G.E. MacDonald, and J. Tredaway Duncar. 2005. Adjuvants. SS-AGR-109. Florida Cooperative Extension Service, IFAS, University of Florida, Gainesville, Fl., 3 pp.

Ferrell, J.A., G.E. MacDonald, and J. Tredaway Duncar. 2005. Principles of Weed Management. SS-AGR-100. Florida Cooperative Extension Service, IFAS, University of Florida, Gainesville, Fl., 7 pp.

Hodges, A.W., W.D. Mulkey, J.R. Alavalapati, D. R. Carter, and C.F. Kiker. 2005. Economic Impacts of the Forest Industry in Florida, 2003. Final Report to the Florida Forestry Association. University of Florida, Institute of Food and Agricultural Sciences, Food and Resource Economics Department and School of Forest Resources and Conservation. 47 pp.

Hornsby, A.G., T.M. Buttler, D.G. Neary, D.E. Short, R.A. Dunn, and G.W. Simone. 1998. Managing Pesticides for Forest Nursery Production and Water Quality Protection. CIR983. Florida Cooperative Extension Service, IFAS, University of Florida, Gainesville, Fl., 12 pp.

Lowery, R.F., and D.H. Gjerstad. 1991. Chemical and mechanical site preparation. In: Forest Regeneration Manual. M.L. Duryea and P.M. Dougherty (eds.). Kluwer Academic Publishers, Dordrecht, The Netherlands: 251-261.

McNabb, K. 1996. Forestry Herbicide Facts. ANR-0629. Alabama Cooperative Extension System, Auburn University, Al., 10 pp.

McNabb, K. 1997. Environmental Safety of Forestry Herbicides. ANR-0846. Alabama
Cooperative Extension System, Auburn University, Al., 6 pp.

Minogue, P.J., R.L. Cantrell, and H.C. Griswold. 1991. Vegetation management after plantation establishment . In: Forest Regeneration Manual. M.L. Duryea and P.M. Dougherty (eds.). Kluwer Academic Publishers, Dordrecht, The Netherlands: 335-358.

Nelson, L.R. and R.L. Cantrell. 1991. Herbicide Prescription Manual for Southern Pine Management. EC 659. Cooperative Extension Service, USDA. Clemson University, Clemson, SC., 56 pp.

Osiecka, A., J. Nowak, A. Long, and M. Mossler. 2005. Herbicides Registered for Pine Management in Florida - 2005 Update. CIR1475. Florida Cooperative Extension Service, IFAS, University of Florida, Gainesville, Fl., 13 pp.

Pesticide Information Profiles (PIPs). 2005. EXTOXNET. http://extoxnet.orst.edu/pips/ghindex.html. (accessed June 8, 2005).

Rao, P.S.C., and A.G. Hornsby. 2001. Behavior of Pesticides in Soils and Water. SL40. Florida Cooperative Extension Service, IFAS, University of Florida, Gainesville, Fl., 7 pp.

Tu, M., Hurd, C., and J.M. Randall, 2001. Weed Control Methods Handbook, The Nature Conservancy. http://tncweeds.ucdavis.edu, Version: April 2001. (accessed March 7, 2005).

Vencill, W.K. (ed.). 2002. Herbicide Handbook. Eight Edition. Weed Science Society of America.

Lawrance, KS.

Young, B. 2004. Compendium of Herbicide Adjuvants. 7th Edition.

http://www.herbicide-adjuvants.com. (accessed March 7, 2005). 